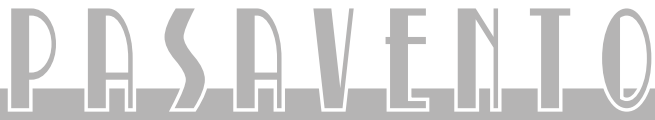

\section{LA AUTORREPRESENTACIÓN DE ANGÉLICA LIDDELL: ¿DEL FEMINISMO A LA MISOGINIA?*}

THE SELF-REPRESENTATION OF ANGELICA LIDDELL: FROM FEMINISM TO

MISOGYNY?

José CoRrales Díaz-PAVÓN Universidad de Castilla-La Mancha

jose.corrales@uclm.es

Recibido:19.03.2021

Aceptado: 17.09.2021

Resumen: Angélica Liddell es una de las creadoras más controvertidas del panorama teatral español e internacional, especialmente desde que su montaje The Scarlet Letter (2018) fuera percibido como un ataque al movimiento Me too y al neopuritanismo del feminismo contemporáneo. Sin embargo, a principios del siglo XXı la propia artista o su entorno más cercano defendían posturas abiertamente feministas. En este artículo quisiera explicar las razones de este giro y de la creación de una retórica misógina como parte de la figura pública de Angélica Liddell, retórica estrechamente vinculada a los cambios en su concepción del arte, del papel de la artista en la sociedad y a la evolución social del feminismo. Así, al mismo tiempo que Liddell abjura de una visión activista y abiertamente política del teatro y lo reconceptualiza en términos anticolectivistas e irracionales, el auge de la Cuarta ola del feminismo sitúa las demandas de igualdad entre géneros en el centro del tablero político. De esta forma, Liddell utiliza una serie de estrategias, como el menosprecio de la feminista puritana y defensora de la cultura de la cancelación o la exaltación de un amor de tintes místicos que exige la sumisión de la mujer al hombre, para definirse como artista según sus postulados individualistas, contrarios a la visión racional del ser humano y, por tanto, a cualquier forma de feminismo organizado.

Palabras Clave: Angélica Liddell, misoginia, Cuarta ola del feminismo, puritanismo, cultura de la cancelación

\footnotetext{
* El siguiente trabajo se ha realizado gracias a la financiación del programa propio de contratos predoctorales de la Universidad de Castilla-La Mancha, susceptible de cofinanciación por el Fondo Social Europeo [2018/12504].
} 
ABSTRACT: The Spanish artist Angélica Liddell is one of the most controversial creators of the international theater circuit, specially since her play The Scarlet Letter (2018) was understood as an attack on the feminist movement Me too and the neopuritanism it carried. This play offers a stark contrast with some previous Liddell's texts that are clearly aligned with a feminist world view, such as La casa de la fuerza (2009). How did a swerve like this happen? In this paper I would aim to explain it as related to a change in Liddell's conception of the purpose of the art and as a response to the rise of the fourth wave of feminism. The adoption of a misogynistic rhetoric by the artist is contemporary with the abandon of her previous trust in the power of an openly political theater, whose place is now occupied by a faith in the art as an approach to the irrational and dark materials of the human soul. This change implies a deeply individualistic approach to the art, opposite to the claims of feminism, and favors the contempt of the puritan feminist and the defenders of the cancel culture.

KEYWORDS: Angélica Liddell, misogyny, fourth wave of feminism, puritanism, cancel culture.

\section{*ath}

La imagen pública de Angélica Liddell está marcada por su ubicación en la cúspide de la vanguardia teatral internacional: en su regreso a los escenarios españoles, en 2018, después de cuatro años de voluntaria renuncia al montaje de sus obras en nuestro país, la periodista Raquel Vidales señalaba que el público madrileño había echado de menos "su provocación, su impudicia" (Vidales 2018). Ella es, según expresiones tomadas de nuevo de la prensa generalista, "la enfant terrible de la escena nacional" (Cultural 2007), "la francotiradora por excelencia de la escena española" (Vicente 2019), "una de las creadoras más disidentes del panorama internacional" (Jiménez 2020).

A partir del estreno de The Scarlet Letter (2018) un nuevo adjetivo se unió a la lista: misógina. Tanto Julio Enrique Checa Puerta (2019) como Cristina Oñoro Otero (2021) explican las circunstancias que Ilevaron a que ese espectáculo fuera entendido como un ataque al movimiento Me too, la reacción de la prensa y la pertinencia de esta interpretación. Remito a esos estudios para conocer en mayor detalle la reacción que suscitó, pero creo relevante exponer la opinión del crítico Marcos Ordóñez, quien, en su crítica del montaje de The Scarlet Letter del verano de 2020 en Barcelona, dice: "el discurso de la oficiante parece chapotear en lo ultramisógino: bofetadas contra mujeres que son 'pura amargura y maldad'. ¿Por qué? Por lo visto, porque son 'mayores de 40 años, rabiosas por la pérdida de la juventud'" (Ordóñez 2020; la cursiva es mía). Ese parece da lugar a la duda, y quien solo conociera los textos iniciales de Liddell se sorprendería de que pudiera ser calificada de misógina. Gumersindo Puche, que todavía hoy acompaña a Liddell en la compañía Atra Bilis, que ambos fundaron, hablaba en 
2007 en estos términos de Lesiones incompatibles con la vida, una acción performática que había tenido lugar en 2003:

Liddell interroga la identidad y, mediante su obra, en la que el cuerpo femenino tiene un papel primordial, llega a la memoria de un dolor antiguo. Su presencia en los foros de arte o teatros la convierte en una portavoz de esa parte de la humanidad todavía en proceso de ser "igual" de humana que la otra. (Puche 2007: 31)

¿Qué ha pasado entre medias? ¿Cómo ha llegado a articular un discurso que puede ser calificado de "ultramisógino" una artista que, a través de las palabras de su compañero teatral, se presentaba como portavoz de una postura feminista a principios de este siglo? Los estudios de Checa Puerta y Oñoro Otero se centran en la relación entre The Scarlet Letter y los textos que alimentan el espectáculo, especialmente Una costilla sobre la mesa (2018) y la Trilogía del infinito (2016). Creo, por tanto, relevante completar sus análisis con una revisión de amplio espectro del imaginario femenino que Liddell ha configurado a lo largo de su producción artística para poder responder a esas preguntas.

En tanto que la propia artista ha derruido las barreras entre su obra y ella misma -el carácter autoteatral/de teatro de autoficción de las obras de Liddell ha sido señalado en múltiples ocasiones (Fernández Peláez 2018; Monti 2019; Olivas Fuentes 2019)-, este imaginario femenino está inextricablemente unido a sus estrategias de proyección pública. En algunas entrevistas Liddell ha roto la tradicional vinculación entre escena y ficción, y espacio estraescénico y verdad, y ha establecido la primacía de la Angélica-personaje sobre la Angélica-persona:

En el escenario me quito máscaras y velos, y rompo el pacto de la hipocresía social. En la vida hay que ser falso constantemente porque, si no, iríamos con unas pistoleras en las caderas. El teatro es un acto de profunda libertad donde me siento libre para decir lo que siento. La careta me la pongo cuando salgo del escenario. Ahí es donde empiezo a fingir para sobrevivir. Uno solo puede existir socialmente mintiendo. Sería insostenible siendo completamente honesto. Por eso creo que el escenario es el único lugar donde se puede trabajar con libertad. (en Ávalos 2013)

No es extraño que autores como Checa Puerta (2019: 156-158) utilicen la "parresía" recuperada por Foucault como instrumento de análisis del teatro liddelliano, en tanto que la actitud de total libertad de expresión frente a la urbanidad que demanda la vida civil forma parte de la imagen de Liddell. No solo porque ella lo sostenga en entrevistas, sino porque los espectadores de sus obras aceptan la supresión de la condición ficcional del personaje, aunque ello contradiga la necesaria ficcionalización y semiotización del cuerpo en escena (Olivas Fuentes 2019: 638). Así, Silvia Monti describe la actitud del público ante la vinculación entre artista y obra como la de una aceptación de los términos propuestos por la artista:

... es indudable que, en el teatro de Liddell, pasión, sufrimiento, cólera, indignación, soledad, desolación se perciben como verdaderos sentimientos de la 
autora. La impresión que tiene el espectador es que realmente, cuando Liddell está en escena, vida y espectáculo se funden y se confunden. Esta percepción no deja de experimentarse aun cuando somos conscientes de la gran profesionalidad de esta artista y de su meticulosidad en la preparación de sus espectáculos, tanto como de su perfeccionismo en la escritura de los textos. (Monti 2019: 539)

Por todo ello, para comprender el papel del feminismo en la cosmovisión liddelliana y el lugar que la aceptación y el rechazo de este movimiento ha ocupado y ocupa en la imagen que proyecta como artista tenemos que partir de las diferentes premisas que justifican la concepción del arte de Liddell y su relación con la sociedad, expresadas tanto a nivel teórico como en las propias obras. El contraste entre las citas de Puche y Ordóñez es lo suficientemente llamativo como para justificar una síntesis de la evolución de Liddell, que nos permita contextualizar los diferentes estadios de su propuesta artística.

\section{Bosquejo eVolutivo: el paso a lo confesional y EL GIRO ANTIRRACIONALISTA}

El primer cambio en la práctica artística de Liddell se produce con su progresivo abandono de formas dramáticas ficcionales para privilegiar una propuesta escénica confesional, en la que el mundo ficcional y su propia vivencia se entremezclen de forma indisoluble para el espectador. Varios estudios (Eguía 2017: 424-425) localizan este cambio a principios del siglo xxI, con obras como Monólogo para la extinción de Nubila Wahlheim y extinción, Lesiones incompatibles con la vida (2003) o Mi relación con la comida (2004). Óscar Cornago sintetiza la evolución de la dramaturga como una progresiva unión entre unas caretas cada vez más similares al rostro de la artista y la exposición de su propio dolor:

Así fueron cayendo las caretas para dejar ver otras caretas, cada una más dolorosa que la anterior. A la niña sádica de las primeras obras, que murió tras el Tríptico de la aflicción, le siguió el rostro monstruoso del hombre de Estado, dictadores y militares que poblaban como fantasmas los Actos de resistencia contra la muerte, y a estos le siguió un nuevo rostro, otra careta más, la de la propia Angélica cada vez más cerca de sí misma, más al borde, más a punto de caer. (Cornago 2011: 136-137)

Es interesante esbozar las razones de este cambio de estrategia dramática de Liddell. Según ella misma explicaba, su reticencia hacia la ficción se debe a que esta ha sido colonizada por el poder económico para saturar la realidad de información falsa. Liddell hablaba especialmente de la saturación de la violencia vista por televisión, que insensibilizaba al espectador frente al sufrimiento real (Liddell 2003a: 41-42). Como respuesta a esta insensibilización la dramaturga propone una "violencia poética" que sea capaz de "conmovernos o al menos hacernos comprender un atisbo de verdad" (2003a: 41), concepción de la función del arte en el escenario que se complementaría con la certidumbre de que "la economía es una de las formas del crimen" y otro de los instrumentos de dominación del poder (Liddell 2008a: 92). Dicha violencia poética se concretaría en el "acto confesional", no ficcional, 
como "cúspide del realismo", "beneficiario del individualismo unamuniano, ese que diferencia entre la humanidad y el hombre otorgándole legitimidad a este último" (Liddell 2005: 74).

Son estos los postulados básicos que subyacen a la creación de obras como los Actos de resistencia contra la muerte o Mi relación con la comida. Sin embargo, esta concepción de la violencia poética como forma de defender la individualidad frente a la manipulación cultural y las agresiones económicas del poder se ve confrontada una y otra vez en los textos de Liddell con su eficacia. Así, la autora reconoce que "el creador vive en una paradoja sin solución: comparte la acción rabiosa con un sentimiento infinito de inferioridad. Al fin y al cabo, sabemos que el arte nunca nos convertirá en mejores personas" (2003a: 43), de modo que "la consecuencia lógica sería la desaparición del autor, que consciente de su falta de influencia sobre el sufrimiento humano iría echando al fuego su obra a medida que fuera completando las páginas" (2005: 74-75).

Esta "paradoja sin solución" puede contribuir a explicar el giro hacia el irracionalismo que la artista dio en torno a 2008. Ella misma explicaba que, a pesar de llevar escribiendo la misma obra desde el inicio de su producción:

... es cierto que en mi trabajo hay dos épocas muy diferenciadas. Una época
en la que pensaba que el teatro podía [ser] político, una especie de activismo,
pero pronto me di cuenta de que el alma humana no puede ser explicada
mediante una teoría económica. Ahora me he desvinculado totalmente de ese
teatro funcional y vivo obsesionada por lo invisible, por todo aquello que no
podemos explicar. Me interesa aquello que sucede en lo más profundo de la
conciencia, de los nervios, me interesa la parte pre-racional como respuesta
al racionalismo. Quiero devolver al espectador la intimidad con sus instintos.
(Jabois 2016)

Gran parte de los ensayos compilados en El sacrificio como acto poético se corresponderían con ese teatro funcional, abiertamente político, ${ }^{1}$ por lo que su capacidad explicativa del teatro posterior de Liddell es limitada. De ellos se puede considerar como una transición en este giro a lo irracional "El sobrino de Rameau visita las cuevas rupestres" y, sobre todo, "El sacrificio de Abraham", que, siguiendo la filosofía de Kierkegaard, consuma el cambio de perspectiva de Liddell con respecto al papel de la violencia en el arte. Lo que sostiene es que la misión del arte es la de atacar los tabúes sociales y provocar la angustia de lo irracional en el espectador, de modo que el público pueda llegar a conclusiones morales acerca de su propia naturaleza a través de la suspensión de la ética (2008b: 113-118). Para Liddell lo que nos iguala y nos permite conocer "la materia del alma humana", "las posibilidades de lo humano", es la Pasión, todo aquello que atenta contra lo general (2008b: 117-188) y permite la reconfiguración del mundo mediante el enfrentamiento con las "circunstancias históricas, políticas, sociales y familiares que nos definen" (2008b: 112).

\footnotetext{
${ }^{1}$ Un teatro que habría empezado a cultivar en 2003, alejándose de "una primera fase poética, ritual e intimista para dar a paso a otra de mayor descaro político" (Villora 2009: 7-8).
} 
Uno de los aspectos más interesante de este giro desde el punto de vista de la creación de la imagen pública de la autora es que ella fomentó su difusión más allá de abocetarlo en entrevistas. A diferencia de los ensayos de El sacrificio..., escritos como conferencias o artículos para medios especializados del mundo teatral, y no compilados hasta 2014, Liddell sintetizó sus ideas sobre el arte y el irracionalismo en un texto publicado como columna de opinión en el diario El País a principios de 2016 -recordemos que la propia autora decidió no representar en España entre 2014 y 2018 (Vidales 2018)-. En ese breve ensayo, de la mano de Nietzsche, Bataille y Harold Bloom, Liddell defiende la necesidad de luchar contra el "Estado hegeliano", contra un status quo que el arte y el mundo de la cultura no desafía, sino que refuerza. Liddell se rebela contra la supremacía de los valores sociales frente a los estéticos y concibe la transgresión moral como una forma de llegar a las profundidades del alma humana, lo que concibe como una liberación frente a la represión:

Esa es la transgresión que me interesa, la transgresión de la ley del Estado, sin politización civil, la poesía es antisocial, porque la transgresión trágica conlleva un efecto liberador que es el encargado de medir el grado de represión de una sociedad, el grado de represión de la cultura. (2016a)

Como la misma autora señala, ha pasado de una concepción de un teatro activista, con unos objetivos bastante explícitos (la mejora del alma humana) y de oposición a un poder con una clara dimensión económica, a suscribir una noción del arte como expresión de lo más profundo de la condición humana, velado al acceso racional, y cuyo objetivo sería lograr una liberación que no tiene una inmediata relación con la política, con lo civil, con lo social. Así, sostiene que "no se pueden sustituir los criterios estéticos por objetivos sociales" (2016a). En tanto que el movimiento feminista tiene un indudable carácter civil, social y político, ${ }^{2}$ la desconexión y enfrentamiento entre sus objetivos y el programa artístico de Liddell es manifiesta. En varias de las obras de Liddell la fricción entre la concepción de la mujer, tanto por parte de la sociedad como de la misma artista, y la esencia última de lo humano es utilizada como materia prima en la construcción de su imagen como artista-mujer, por lo que me parece oportuno examinar detalladamente las obras más relevantes a este respecto. No obstante, me centraré en aquellas que preparan su giro hacia una retórica misógina, por lo que piezas destacadas de la producción liddelliana, como el Tríptico de la aflicción o los Actos de resistencia contra la muerte quedan fuera. Para una lectura feminista de estas obras remito a María Francisca Vilches de Frutos (2009) y Celia Martínez Sáez (2017).

\footnotetext{
${ }^{2}$ Carácter que, a efectos de este artículo, sintetizaré como la plena igualdad entre seres humanos e inscribiré dentro del paradigma de la Modernidad. Sin embargo, es importante resaltar que la concepción del feminismo como una corriente moderna se opone a otro de los rasgos fundantes del paradigma moderno, la creación de las esferas de lo público y lo privado, que han permitido la perpetuación de roles de género patriarcales. Para un análisis del feminismo, la Modernidad y estas esferas remito a Marta Postigo (2007).
} 


\section{LA MATERNIDAD Y LA DIGNIDAD: SER MADRE, SER HIJA, SER MUJER}

En el ya mencionado artículo de Gumersindo Puche (2007) sobre Lesiones incompatibles con la vida, el compañero artístico de Liddell trazaba una genealogía de la autora que se remonta al mito de Lilith, la Hester Prynne de Hawthorne y Marina Abramović y esa "corriente que se inicia en los años sesenta con el olvidado eslogan que decía: 'Lo personal es político'" (Puche 2007: 31). Del personaje de La letra escarlata toma la creación de un símbolo que exhibe en público como forma de transformar un castigo en una liberación (2007: 32). En la performance de 2003 la letra escarlata de Liddell es la proclamación de la renuncia voluntaria a tener hijos, que se convierte en protesta corpórea ante la hipocresía social y denuncia del dominio de una concepción economicista del ser humano (Liddell 2003b). Según cuenta Puche, la artista en escena se movía con unos bloques de yeso en los pies, bloques en los que al final del espectáculo los asistentes podían escribir (2007: 32-33). Los mensajes dejados eran en su mayoría reproches de otras mujeres por la decisión de no tener hijos, con lo que se perpetúa el rechazo social a esa posibilidad, también por las propias mujeres (2007: 33). La lectura que hace Puche de este hecho es que, a pesar de que la procreación es un instrumento de dominio social del género femenino, la confesión del deseo de no tener hijos es todavía tabú entre las propias mujeres por la posibilidad de exclusión social que supone (2007: 34).

Liddell va a tomar estos materiales para conformar el personaje de Agnes en la obra Belgrado (2007). Aunque el tema principal de esta obra son los traumas generados por la violencia de la guerra de Yugoslavia en la sociedad serbia, Liddell expresa a través de dos personajes ajenos a la sociedad eslava, los occidentales Baltasar y Agnes, el dolor provocado por la familia y la condición de la mujer. Agnes, además, es el único personaje femenino de la obra, lo que ha favorecido su interpretación como trasunto de la propia Liddell (Monti 2019: 538). Agnes explicará a Baltasar que:

Para hablarte de las madres, Baltasar, tengo que hablarte de las mujeres, puedo hablarte de las mujeres porque soy mujer y ellas son mujeres.

Una mujer no obtiene el respeto de la sociedad católica, porque la nuestra, aunque laica, es una sociedad católica, de moral católica, de prejuicios católicos y mierda católica, no es necesario creer en Dios para vivir según "lo católico", es decir, "lo misógino", tu madre vive según lo católico y lo misógino, no importa la ideología de tu padre, no es una cuestión ideológica, a las mujeres se las trata siempre 


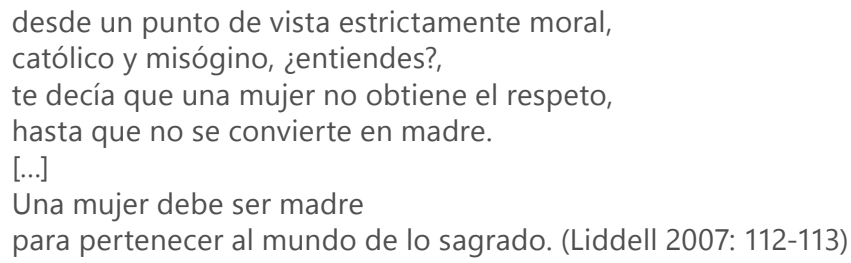

Agnes apunta aquí a un problema sistémico de machismo social (de la sociedad de la que ambos personajes proceden, que no es la serbia, sino una occidental que identificamos con España), con una clara raigambre cultural: la religión católica. Esta, a su vez, polarizaría las posibilidades de lo femenino, de modo que "la moral católica divide a las mujeres en tres,/ paridoras, vírgenes y rameras. La mujer vive sometida a estas tres categorías" (2007: 115). No existe posibilidad de alcanzar un "respeto" que iguale a la mujer al hombre, sino que está sometida o al desprecio de la condición de prostituta o a la sublimación de lo sagrado que impone la de virgen/madre. Sin embargo, el hecho de que sea un condicionante social no impide que Agnes afirme la colaboración del resto de las mujeres en esa situación humillante, tanto más cuando participan activamente en el desprecio de aquellas que desafían la imposición de la maternidad como única vía de acceso a una posición social más digna:

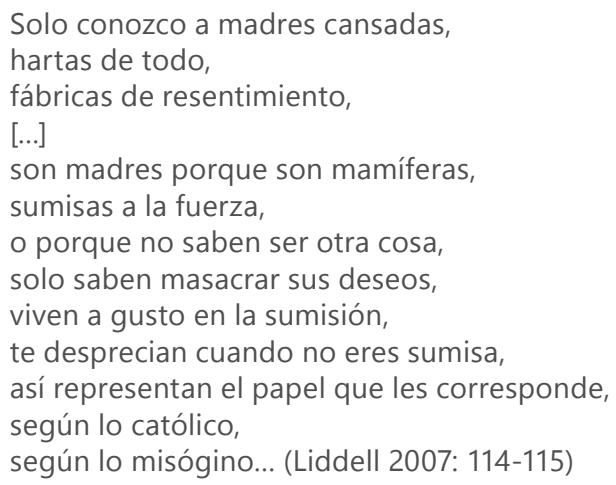

De hecho, Agnes constata el desprecio que otras mujeres le demuestran por no tener hijos, con frases reminiscentes de las escritas por el público en los bloques de yeso de Lesiones incompatibles con la vida (Puche 2007: 32-33) -"cuando llegues a vieja estarás sola,/ es lo mejor que me ha pasado en la vida,/ no sabes lo que te pierdes" (Liddell 2007: 114)-. La conclusión de Agnes es que la misoginia conduce a la expulsión de la mujer de la vida intelectual y su reducción al mundo de los sentimientos, de modo que "tomando posesión de lo intelectual,/ el hombre se asegura el derecho a estar por encima de la mujer" (2007: 115).

Hasta aquí la concepción liddelliana de la desigualdad entre hombres y mujeres coincide a grandes rasgos con el diagnóstico social que la achaca a causas culturales presentes en la sociedad española: es una explicación racional 
que permite articular estrategias que, también desde la cultura y el arte, sirvan de denuncia y contribuyan a acabar con esa lacra. Sin embargo, el giro hacia lo irracional en la concepción del arte de Liddell justificaría la evolución de la autora hacia el abandono de cualquier tentativa de explicación de la condición humana según parámetros racionales, abandono que afecta irremediablemente a su visión de la naturaleza femenina.

Lo que a partir de ahora Liddell privilegiará en su cosmovisión del ser humano es la idea de que a través de las pasiones, de aquello que no queremos ver de nosotros mismos, es como llegamos al conocimiento más profundo de nuestra naturaleza. Esta idea se manifiesta con fuerza en Todo el cielo sobre la tierra, cierre de El centro del mundo (2014), obra en la que Liddell carga contra "los profesionales de la piedad [...] los destinados a la salvación del mundo moderno" (2014: 164-165), los que acumulan un "suplemento de dignidad" que les hace creerse mejores que los demás (2014: 165). Así, si en Belgrado la reducción de la mujer al mundo del sentimiento y la obligación de la maternidad eran imposiciones de la sociedad misógina, en Todo el cierro sobre la tierra la vertiente de denuncia social se pierde y se mantiene la idea de que hay un sector de las mujeres que acepta deliberadamente esa reducción a un ser sentimental, y que busca en el sacrificio (en el que se incluye la maternidad) una ganancia moral:

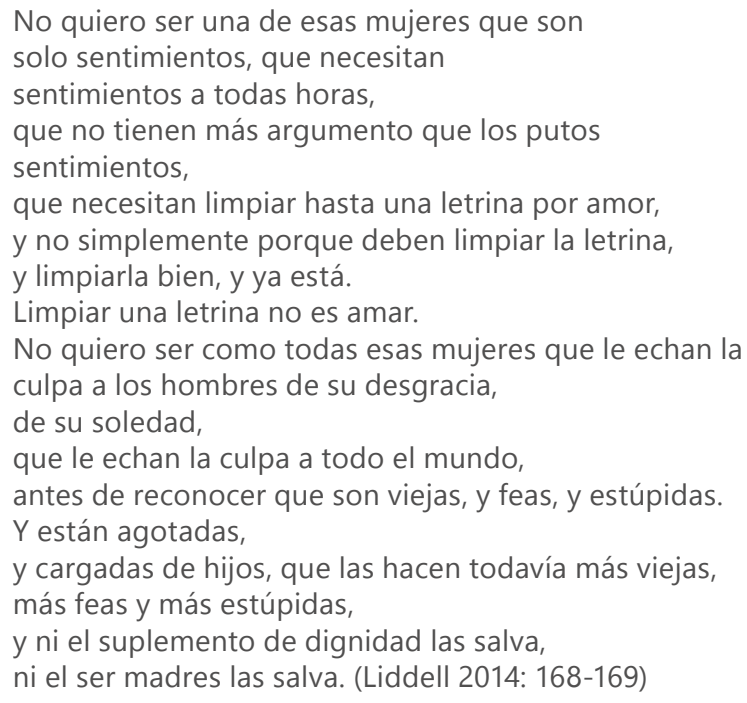

En este fragmento se percibe una de las razones por las que Liddell dibuja un retrato colectivo de las mujeres desde su ángulo menos favorecedor: sirve como contraste y forma de diferenciación de la artista, como manera de afianzar su radical individualidad frente a un "ellas" que buscan la dignidad en la convencionalidad. Obras como Ping Pang Qiu (2013) -incluida en El centro del mundo (2014)- o Una costilla sobre la mesa (2018) incluyen claros alegatos contra la supresión de la individualidad en aras de lo colectivo, de lo social, que en algunos momentos 
de la producción de Liddell, como en las obras contenidas en el Ciclo de las resurrecciones (2015), toma la forma de un ataque a su madre. ${ }^{3} \mathrm{Si}$, como hemos visto, a principios del siglo xxı la cuestión femenina para Liddell tenía que ver con el rechazo a tener hijos como forma de desafiar el dominio masculino, después de su giro antirracionalista la dramaturga carga contra su madre, a quien achaca los rasgos más banales de su carácter, que acaban por extenderse a todas las mujeres:

Debo soportar una misoginia feroz que asumo sin culpabilidad porque en casi todas las mujeres reconozco rasgos de la mujer que me crio, en ella patológicos, en el resto de las mujeres lo que las unifica, lo que las hace pertenecer a un género, la suspicacia, el parloteo y la malicia, y la mentira y la absoluta falta de nobleza, entrometidas, malhumoradas, venenosas y rastreras, siempre agobiadas, ansiosas, torpes, desmemoriadas, horriblemente susceptibles, más testarudas de lo que nadie puede resistir, y la mayoría de las veces incapaces, y dispuestas a echarle la culpa a cualquiera antes que reconocer su incapacidad, convencidas siempre de llevar razón y de saberlo todo y de hacerlo todo bien para compensar su verdadera falta de inteligencia. Cuando reconozco alguno de estos rasgos en una mujer el rechazo es tan intenso que acaban por saltárseme las lágrimas como si me estuvieran sometiendo a una tortura física. Enfrentarme a lo comúnmente femenino me produce verdadero asco. (Liddell 2015: 130-131)

La exhaustiva enumeración de las bajas pasiones que caracterizarían "lo comúnmente femenino" le sirve para marcar el contraste con los sentimientos extremados que cifran lo humano. Porque la evolución de la cosmovisión liddelliana la lleva a rechazar, incluso en ella misma, todo lo que sea mediocre. Ello propiciará que en el Ciclo de las resurrecciones y en Una costilla sobre la mesa Liddell utilice un lenguaje de desprecio de ella misma y del resto de las mujeres que bebe de la mística y que imposta el amor extremado hacia un amado divinizado y la sumisión a él como una actitud loable, en abierta oposición a la idea de la emancipación femenina.

\section{LA MÍSTICA Y LA SERVIDUMBRE VOLUNTARIA: EL RECHAZO DE LA MUJER MODERNA}

La consolidación de un ideal femenino que no se ajusta a los parámetros de la Modernidad es una de las constantes que recorren las obras que conforman el Ciclo de las resurrecciones, ${ }^{4}$ y que, como veremos, se extiende a la Trilogía del infinito y Una costilla sobre la mesa -textos que alimentaron el espectáculo The Scarlet Letter, según los ya aludidos estudios de Checa y Oñoro-. En el Ciclo de las resu-

\footnotetext{
${ }^{3}$ Algo que no se corresponde con lo que la autora escribe actualmente: la muerte de sus padres, cuya agonía reflejó en Una costilla sobre la mesa (2018), y el duelo por esta muerte, literaturizado en Dicen que Nevers es más triste (2020), han propiciado que Liddell hable de ellos desde una posición más comprensiva.

4 Obra que reúne los textos de diversos espectáculos, como Primera carta de San Pablo a los corintios, You are my destiny (Lo stupro di Lucrezia) o Tandy, pero también La novia del sepulturero. Diario, texto del que proceden gran parte de los anteriores. Para evitar excesivas aclaraciones sobre los trasvases entre ellos -frecuentes, sobre todo, del diario al texto de los espectáculos- los trato como si fueran una unidad.
} 
rrecciones Liddell establece un diálogo con la tradición religiosa occidental que va desde los títulos -además del de conjunto, Liddell nombra dos de sus piezas con reminiscencias bíblicas: Primera carta de San Pablo a los corintios y Salmos- hasta, fundamentalmente, la creación de un imaginario místico que reconceptualiza lo femenino para que pueda servir como acceso a ese núcleo ajeno a lo racional en el que se puede encontrar alguna verdad sobre el ser humano. Posiblemente el extracto más claro al respecto sea este:

... porque somos cientos, arrodilladas sobre esa escalera de mármol centenario capaz de guardar el secreto y la vergüenza de esta carne de mujer, retraída ante los hombres pero que no se arredra al declarar su amor ante Dios y ante los ángeles, ante las más altas cumbres de la divinidad, somos cientos, escupidas por la realidad insoportable y recogidas hechas pedazos por lo divino, porque la realidad insoportable atrofia el sexo, pero lo divino lo exalta, y es ante lo sagrado donde la carne femenina, menos que carne, se siente libre para confesar esa magia en la sangre, el amor, el rapto de la sangre, sin temor a la burla, sí, más libre ante Dios que ante los hombres, más cerca de Dios que de los hombres, porque hay algo mediocre en lo terreno y maravilloso en lo absoluto, y es el ansia de absoluto lo que nos hace desgraciadas en los eriales de la realidad, concebidas para el éxtasis, para la locura mística, para el delirio sexual, para el abandono salvaje y la antropofagia, descendientes de ménades, inútiles para la frialdad y el cálculo de la razón, nos refugiamos en la gloria, que a menudo acaba siendo nuestra miasma. (Liddell 2015: 190)

Liddell reinventa aquí uno de los tópicos más persistentes sobre las mujeres: su carácter intrínsecamente irracional. Es una reinvención porque invierte el carácter peyorativo que esta presunta característica femenina ha impuesto: el ser "descendientes de ménades, inútiles [...] para el cálculo de la razón" no las hace seres humanos inferiores, sino superiores, les permite elevarse hacia lo absoluto en contraposición a la mediocridad de la realidad y de los hombres, lo que las lleva al terreno de lo divino. La "locura mística" que Liddell reclama es la que le permite divinizar al amado y construir su relación como una de total sumisión, en la que Liddell menoscaba su autonomía en su búsqueda de sentido en lo premoderno. Así, en Primera carta de San Pablo a los corintios describirá la relación con imágenes claramente deudoras de la creación de Eva:

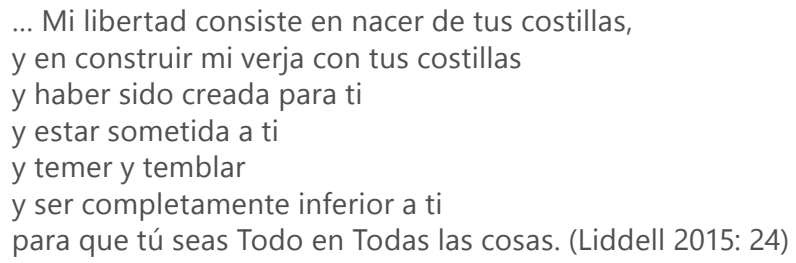

Es coherente que poco después Liddell proclame que "no entiendo a esas mujeres que reclaman sus derechos/ por encima del hombre,/ porque yo encuentro dulzura en estar hecha para el hombre" (2015: 25). Este amor divino y humano permite a 
Liddell separarse de los hombres, de la comunidad, siguiendo las palabras de Jesús (Mateo 10, 34-38) sobre el amor a Dios por encima del amor a la propia familia (Liddell 2015: 25-26). Este amor que destruye los vínculos con sus semejantes además le permite fundamentar su parresía, su actitud de hablar sin tapujos, tanto de su madre como de "la gente detestable", entre las que, como hemos visto, están las mujeres en general:

Creo que desde que te amo me atrevo a más, me atrevo a llamar egoísta, mentirosa, retrasada y mala a mi madre, me atrevo a todo eso sin sentimiento alguno de culpa, porque tengo tu espíritu, tu espíritu, y tu espíritu me acompaña en el valle tenebroso, me atrevo a detestar sin pudor a la gente detestable porque tengo tu espíritu y ya me da igual todo, nada tiene importancia salvo tu espíritu.

No hay servidumbre en la tierra que me retenga.

No hay cosa material que me aconseje prudencia.

Solo me dedico a ti. (Liddell 2015: 26)

Sin embargo, podemos preguntarnos si Liddell ha tomado verdaderamente el camino de vuelta de la Modernidad, si en sus obras no hay nada que desactive la construcción de este imaginario de sumisión, en las antípodas de aquel rechazo de lo católico por misógino que sostenía en Belgrado. El principal argumento en contra de una vuelta total a la moral católica como regidora de la vida social y del comportamiento femenino la encontramos en las mismas páginas de las obras del Ciclo: "no encuentro mayor herejía que comportarme como si Dios existiera a sabiendas de que no existe" (2015: 66); "reclamo lo sagrado frente a lo ridículo, frente a la sorna que todo lo empobrece. Reclamo lo sagrado. Reclamo el mito" (2015: 119). Esta reclamación es solidaria con su necesidad de un interlocutor, que es un sustituto del sentido de su escritura: "yo solo puedo escribir si escribo para alguien, si escribo para amar a alguien [...] Necesito un interlocutor sentimental, aunque sea imaginario, puesto que mi vida interior está absolutamente desconectada de mi vida exterior" (2015: 116). El lenguaje místico que utiliza no se dirige realmente a alguien, es un puro ejercicio de voluntad necesario para escapar de la parálisis de la escritura, como lo es la necesidad de inventar un Dios. Pero el hecho de que esta instancia sea masculina permite a Liddell desear que "mi soledad fuera masculina, entonces sería una soledad hermosa [...] Me da asco esta soledad con olor a mujer" (2015: 185) y preguntarse "¿qué error hubo en mi nacimiento? Oh, amado mío, ¿por qué pertenezco al sexo que detesto?" (2015: 185), hasta volver de nuevo a la exaltación de la desigualdad entre el amado hombre y la mujer-Angélica: "no me queda más remedio que amar como mujer. Perdóname si amándote no soy más que una mujer" (2015: 185).

Así, la descripción que Liddell hace de sí misma es la de un ser alienado con respecto a la sociedad (la existencia, la realidad, que siempre se relaciona con los otros). Solo desde su búsqueda de lo sagrado y la oposición a los valores que rigen la sociedad contemporánea se entiende el anhelo de Liddell por la subyugación, por la inferioridad y el sometimiento de su voluntad: "yo miro al 
blasfemo y veo a un redentor, y mis rodillas se clavan sin que mi voluntad intervenga, se clavan en el suelo para adorar su blasfemia. Y así, arrodillada, gozo de un reconfortante sentimiento de inferioridad" (2015: 117).

Posiblemente debamos tener en cuenta el hecho de que Liddell juega deliberadamente en las obras del Ciclo con un diagnóstico clínico, fusionado con una referencia literaria. Junto con las referencias bíblicas y místicas, otro texto que sirve de referencia a Liddell en el Ciclo de las resurrecciones es la novela de Sherwood Anderson Winesburg, Ohio. Liddell titulará una de las obras del Ciclo con el nombre de uno de los personajes de Anderson, Tandy, en el que cifrará la entrega voluntaria a un amor absoluto que la dramaturga identifica con el síndrome de Clérambault. La dramaturga española toma de la obra Anderson la idea de que los hombres necesitan mujeres lo suficientemente fuertes para atreverse a ser amadas (Liddell 2015: 59-60; Anderson 1990: 198-200). Liddell construye la idea de que ella es lo suficientemente fuerte para amar mediante la relación mística con el amado, pero afronta la posibilidad de que sus visiones y sentimientos sean "simplemente el conjunto de síntomas de un delirio psicótico" (2015: 148). Sin embargo, se opone a la reducción de su pasión a "una descripción clínica a manos de esos expertos asesinos de poesía" (2015: 68). Frente a la consciencia de esta alteración mental y la expulsión de la vida de cualquier atisbo espiritual, Liddell reafirma su voluntad de trascendencia, dado que los médicos "nunca comprenderían que hay un momento en la vida en que necesitas rezar para sobrevivir a la ausencia de amor [...] y necesitas inventar dioses y buscar a gente que vea los mismos dioses que tú" (2015: 147).

El contextualizar su visión del mundo, del amor y la idea de la sumisión de la mujer al hombre en el marco de un trastorno mental (que la artista reivindica como mejor que la mediocre normalidad) pudiera parecer una salida conceptual para explicar la imagen misógina que Liddell proyecta. Sin embargo, el propio discurso de Liddell evidencia que se trata de una elección: ella misma expone que sus opciones para comprender y explicar los tormentos que padece son considerarse o una enferma o una maldita (2015: 206-207); y, en un arrebato de lo que desde el punto de vista de un lector ajeno a su universo podría ser considerado lucidez, ella misma esboza lo negativo de su reclamación de la locura:

... no sé cómo he llegado a este reino imaginario de idiotas atormentados, los creyentes, desesperados que inventan sus propios dioses para no volverse locos en vano [...]. No sé cómo he llegado a este valle de altares ridículos [...] este refugio falsamente sagrado, esta invención insana que solo me acerca a la boca falsamente profética de los retrasados, porque necesitamos señales, maldiciones y profecías para sentir que no estamos enfermos y sin esperanza, y sin embargo cada señal inflama la enfermedad y la falta de esperanza, y acabamos por convertirnos en una figura grotesca, y las muecas de adoración no son más que las horribles huellas de este puto sufrimiento ininterrumpido que solo admite lo imaginario por ser la realidad insoportable, cargada de seres humanos insoportables ... (Liddell 2015: 204-205) 
Aun cuando el fragmento anterior muestra que el rechazo del paradigma racionalista del ser humano por la vía de la reclamación de lo sagrado es también un callejón sin salida, producto de la necesidad de escapar de una realidad insoportable y no de una verdadera alternativa estética y ética, Liddell continuará cultivando una retórica (que incluye una visión negativa de la mujer como género y una exaltación de la sumisión al hombre amado) que le permite evitar la parálisis conceptual a la que la condujo la pérdida de la fe en la capacidad política del teatro. Ello explica que a pesar de la consciencia de su conversión en una "figura grotesca" cuyas muecas y ansias de lo sagrado no responden sino a un intento por lidiar con el sufrimiento, Liddell persevere en esta retórica mística que lleva aparejada una importante carga misógina.

Los tonos místicos que utiliza en el Ciclo de las resurrecciones pervivirán en la Trilogía del infinito y Una costilla sobre la mesa, los textos sobre los que se basa The Scarlet Letter. Como disponemos de los análisis de Checa y Oñoro, no me detendré en exceso en estos textos, ${ }^{5}$ aunque sí merece la pena comentar algunos aspectos que contribuyen a ilustrar la tesis aquí sostenida de que la retórica misógina de Liddell procede de su rechazo conceptual a la condición de ser humano que impone la Modernidad. En su estudio sobre The Scarlet Letter Cristina Oñoro sostiene que el principal elemento de misoginia de la obra no es su ataque indirecto contra el "feminismo mainstream" sino "la genealogía de grandes maestros que reivindica y en la mitología creada en torno a la figura del artista y la creación" (2021: 74). Por cuanto están vinculados con la imagen de la mujer que Liddell desprecia y la que canoniza me interesa señalar el empleo concreto de dos de los integrantes de esta genealogía: el filósofo Friedrich Nietzsche y la protagonista de La letra escarlata, Hester Prynne.

\section{Entre Nietzsche y Hester Prynne: contra la cultura de la cancelación}

En ¿Qué haré yo con esta espada?, una de las obras de la Trilogía del infinito (2016b), encontramos un segmento titulado "Solo gli uomini sono belli fino alla fine dei loro giorni" (2016b: 131-137). En este segmento -que, en parte, se reprodujo en The Scarlet Letter (Checa 2019: 167)- Liddell contrapone la belleza inmarcesible de los hombres a la degradación de la belleza física (por su degradación moral) de las mujeres. En este texto Liddell introduce a su vez una aclaración entre paréntesis sobre la naturaleza de las mujeres:

(siempre mujeres antes que seres humanos por sentirse ellas ajenas a las taras de los seres humanos y a las debilidades de los seres humanos, superiores, como si hubieran nacido de la probeta impoluta

\footnotetext{
${ }^{5}$ Vale la pena comentar que Checa Puerta señala que, analizando el tratamiento crítico del texto publicado y el del espectáculo escénico, el lenguaje lírico y místico de Una costilla sobre la mesa no trasciende en la representación, de modo que los espectáculos pierden "toda su capacidad por indagar en el misterio y se han recibido como un exabrupto, una provocación" (2019: 165).
} 


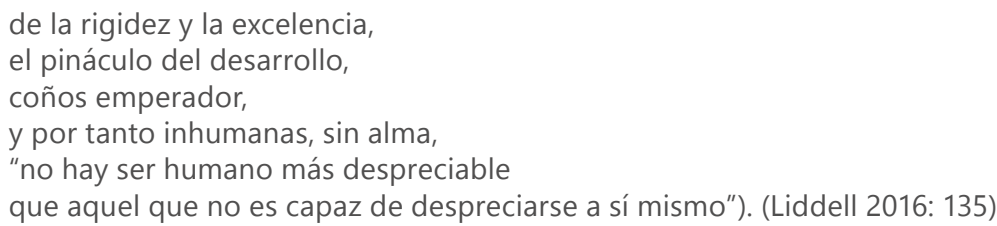

La cita con que cierra el paréntesis procede de Así habló Zaratustra de Nietzsche (2010: 26). Con ella Liddell ilustra el camino cognoscitivo que defiende para el ser humano: el del "desprecio de uno mismo", la huida de la imposición del modelo de ser humano que prescribe la Modernidad, ese "pináculo del desarrollo" que sugiere la culminación de un proyecto de supuesto progreso que Liddell, de la mano de Nietzsche, desprecia. La solidaridad que Liddell establece entre el ataque a las mujeres y Nietzsche tiene diversas lecturas, en tanto que la obra del filósofo alemán puede leerse desde las múltiples declaraciones misóginas que contiene o, según la interpretación de Sarah Kofman, desde una interpretación del ataque nietzscheano a los valores y la moral establecidos que sea fértil para la deconstrucción y crítica del patriarcado (Barly 2020). El propósito de Liddell cuando denuesta el afán de perfección del feminismo puede ser comprendido, por tanto, como una reedición de la ofensiva de Nietzsche contra la moral del esclavo y la victimización de los débiles.

Nietzsche es, así, una de las principales figuras de esa genealogía que la dramaturga reivindica. De hecho, en un alegato contra la "cultura de la cancelación" incluido en Una costilla sobre la mesa -alegato que también formará parte de The Scarlet Letter (Checa 2019: 168-169)-, nombra a Nietzsche entre los autores amenazados por esta "cultura de la cancelación" que el puritanismo feminista (presuntamente) impone. La dramaturga, opuesta a los "puritanos progresistas que secuestran la naturaleza y lo bello relegando la oscuridad que rige nuestras almas al estrado superficial de los censores modernos" (2018: 54-55), enumera aquello y aquellos que están en peligro ante su envite:

\begin{abstract}
¿Darán por cancelada la lujuria, la perversión y los vicios que también nos definen y nos liberan? ¡Oh, Foucault! ¿Llegarán a censurar por degenerados incluso nuestros sueños, borrarán el hecho degenerado del inconsciente? ¡Oh, Freud! ¿Qué obras degeneradas eliminarán de los museos y las bibliotecas? ¡Oh, Genet! ¡Oh, Nietzsche! ¡Oh, Sade! ¡Oh, Nabokov! ¡Oh, Tiziano! ¡Oh, Caravaggio! (Liddell 2018: 55)
\end{abstract}

El campo semántico, con las perífrasis "dar por cancelada" o "llegar a censurar", nos llevan a pensar, indudablemente, en el concepto de "cultura de la cancelación", que para Liddell supone un ataque a la propia esencia de lo humano: lo que se quiere borrar no son ciertas obras de arte y de cultura, sino una cierta visión del ser humano que resulta incómoda por "degenerada". Se trata de una caracterización del feminismo contemporáneo como intransigente y pacato que ha tenido cierto éxito como forma de denostarlo. Aunque no utiliza el concepto "cultura de la cancelación", Lucía Lijmaer proporciona un interesante análisis de 
cómo se ha relacionado el supuesto resurgir del "puritanismo" con el feminismo, especialmente en el ámbito de la cultura. Así, en el capítulo titulado "Cuando las neopuritanas son las demás" de su libro Ofendiditos. Sobre la criminalización de la protesta (2019), sostiene:

... las acusaciones de puritanismo hoy se suelen producir en un ámbito muy concreto: los debates acerca de supuestas conductas inapropiadas, generalmente de tipo sexual, en el mundo de la cultura. De las últimas polémicas culturales que han sido calificadas de puritanas, las más notables son: la relectura de Lolita de Nabokov por parte de ciertas académicas feministas, el revuelo por una exposición del pintor franco-polaco Balthus o el [...] caso de Egon Schiele. (Lijmaer 2019: 20)

Para Lijmaer, la clave de bóveda de la reacción antifeminista es la percepción, por parte de las sedicentes "no puritanas", de que el feminismo contemporáneo trata a los adultos como si fueran incapaces de formular sus propios juicios éticos al margen de la moral colectiva. Ello implicaría "la perpetua victimización e infantilización de todas las mujeres" y el menoscabo de la libertad individual (2019: 28-29), especialmente en el mundo del arte y la cultura: "se tacha de neopuritano a quien señala una victimización y señala o censura (por ese orden de gravedad) una ofensa de tipo sexual en una obra artística" o a quien "pone en discusión la moral sexual de un creador" (2019: 30). ${ }^{6}$

La caracterización del puritanismo de Liddell no es, por tanto, exclusiva de la autora, sino que pertenece a una corriente más amplia con la que comparte el temor por la pérdida de toda una tradición cultural-Nabokov, por ejemplo-y un léxico similar con el que dibujar a un enemigo que se caracteriza por su afán censor y la victimización. Así, Liddell relaciona directamente esta actitud censora con uno de los prototipos deformados de la mujer feminista: las "profesoras con su irreprochable superioridad, misándricas totalitarias, intrascendentes y anodinas, víctimas por decreto" que declaran que "lo que antes NO era ley ahora sí lo es" (2018: 56). No es difícil distinguir en esa "conversión en ley", en esa "victimización por decreto", el eco de las críticas que se han vertido sobre la legislación promulgada para luchar contra el machismo sistémico.

La dramaturga no menciona directamente el feminismo, pero sí habla de "los tribunales invisibles de la corriente de los tiempos que condenan al ostracismo todo aquello que les parece nauseabundo" (2018: 56), condena permitida por la deliberada confusión entre ideología y ley y la extensión de esta confusión al mundo del arte. Para ella, "la ideología es lo contrario del pensamiento" y todo intento de reducir el arte a ideología (como ocurrió con el calvinismo o con el marxismo) un intento de destruir la energía del espíritu (2018: 56). Liddell se opone a la obligación de un arte moralmente intachable convirtiéndose en una nueva Hester Prynne:

\footnotetext{
6 Por el contrario, la posición de Lijmaer es que tras las acusaciones de "puritanismo" o el menosprecio de lo "políticamente correcto" late un intento de exagerar lo anecdótico como forma de apartar la atención de la opinión pública de los verdaderos problemas sociales, como el machismo o el racismo.
} 
Mi letra A sigue siendo un estigma por ofensas a la moral. Mi hija, mi obra, mi Pearl, ha entrado en conflicto con el estado puritano o tal vez nace del propio conflicto con el estado puritano [...]. No es la A de ADÚLTERA, es la A de ARTISTA. Cantamos a la consagración de la libertad en su lucha contra el despotismo blanco y la guardia de las buenas costumbres. (Liddell 2018: 56-57)

Sin embargo, Liddell no teme verdaderamente por el fin del arte. Para ella "todo aquello que intenta acabar con el alma tiene su efecto contrario, la alienta" (2018: 56), y "la A termina por ser un bien y la transgresión un beneficio. A través del arte, de esa A bordada, lo inmoral es ético, revierte en el bien común" (2018: 57). Ello justifica su propia actividad artística:

Es finalmente el ARTE el que me obliga a coser la letra escarlata y llevarla en el pecho en ese patíbulo-escenario que es toda misa trágica. La conciencia del hombre no pertenece al Estado, ni a la ley, ni a la opinión general, ni al activismo, ni a las proclamas, ni a la voluntad de los pueblos. (Liddell 2018: 57)

La concepción del arte de Liddell está así indudablemente unida a su proyección como artista en ese "patíbulo-escenario" desde el que se opone a la supeditación del alma al activismo. Proclama que "acepto el veredicto de la comunidad ofendida cosiendo la letra sobre mi pecho" (2018: 57), pero también manifiesta que el orgullo que le genera la apropiación de la ofensa a la comunidad le provoca una "oscura, compleja y antigua sensación de pecado. Un sentimiento de depravación, de tendencia incurable", una herida íntima de la que depende el orgullo, y viceversa (2018: 57). Liddell vincula así lo que Checa denomina "la actitud del parresiastés, o de la propia Hester Prynne" (2019: 180) (con cursivas en el original) con el dolor y la individualidad que recorre toda su obra, y que ha asociado a su propia persona. Liddell no es indiferente a nivel personal a los ataques al activismo feminista que escribe o pronuncia en escena: según ella misma sugiere, al enfrentarse a la comunidad experimenta una "depravación" que estaría claramente relacionada con la exploración de las pasiones más bajas que, de la mano de Nietzsche, concibe como acceso a la esencia de lo humano. A ello se une una posición artística claramente contraria a la "cultura de la cancelación" en tanto que Liddell cifra en el arte y la filosofía supuestamente amenazados por esta práctica (abanderada por el feminismo más combativo) la ganancia ética que obtenemos al entrar en contacto con lo más profundo de nuestra condición.

Es de resaltar la resignificación que se ha producido de la figura de Hester Prynne, resignificación que resume la evolución de Liddell: si en 2007 Gumersindo Puche podía usar al personaje de Hawthorne como emblema de la defensa de Liddell de una clara posición política, en torno a 10 años después la propia artista utilizará a la protagonista de La letra escarlata como adalid de la autonomía del arte con respecto a la mejora colectiva y el activismo social impuesto por una moral feminista puritana -al igual que la Hester Prynne de Hawthorne se enfrentaba al puritanismo de la Nueva Inglaterra del siglo XVII-. Si la primera Hester estaba hermanada con Lilith en su actitud de parresiastés frente a la supeditación de la dignidad humana a la economía, en Una costilla sobre la mesa 
Liddell indicará que, para Harold Bloom, ${ }^{7}$ la creación de Hawthorne es una "Eva estadounidense" (Liddell 2018: 50), y empleará la figura de Eva en varias ocasiones como modelo para su relación mística (de hecho, ya el título de la obra preconiza las referencias a Eva). Es, hasta cierto punto, lógico que las figuras de Eva y Hester confluyan, en tanto que ambas comparten la supeditación al hombre por causa del amor -ya en el Ciclo de las resurrecciones Liddell citaba fragmentos de La letra escarlata (2015: 165)-.

Hasta aquí he dibujado un panorama coherente de la evolución de la relación de Liddell con las posturas feministas; evolución que estaría en íntima relación con sus postulados artísticos y con la cronología del auge y la reacción a la "corriente de los tiempos" que sería la Cuarta ola del feminismo: así, Nani Aguilar Barriga sostiene que esta Cuarta ola se encuadra entre 2011 y la actualidad (2020: 137), mientras que Lucía Lijmaer señalaba en 2019 que el discurso que relaciona censura, puritanismo y lo políticamente correcto se habría instalado en la opinión pública hace menos de una década (2019: 18), década en la que la imagen que Liddell dibuja del feminismo está caracterizada por su denuesto y oposición. Sin embargo, para que este panorama de la aproximación liddelliana al feminismo y su influencia en la creación de su figura pública fuera completo faltaría la exposición de lo que al respecto nos dice una de las obras más conocidas de Liddell, la más difícil de integrar en el discurso explicativo que estoy proponiendo: La casa de la fuerza (2009).

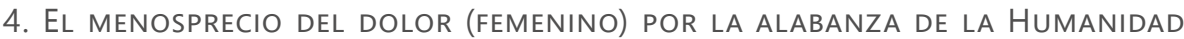 (MASCULINA): LA CASA DE LA FUERZA}

La casa de la fuerza fue la obra mencionada por el jurado del Premio Nacional de Literatura Dramática para concederle el galardón a Liddell en 2012 (Cultura y Deporte 2012). Aunque no explicitaron los motivos, análisis como el de Antonio Morón resaltan que la obra "supone una reflexión profunda acerca del significado de la violencia machista en la sociedad del siglo Xxı" (2017: 432). Mediante la utilización de documentos relacionados con los feminicidios de Ciudad Juárez, mezclados con la experiencia subjetiva de Liddell, la autora construye un discurso feminista radical que es "aceptado por la sociedad en su planteamiento teórico" (Morón 2017: 441) y que orbitaría en torno a la exposición de "la perversión machista que hace el hombre de la realidad, lo cual lleva a la autora a pedir su extinción" (2017: 440). Se trata de una obra polimorfa, en la que Liddell mezcla canciones de La oreja de Van Gogh, corridos mejicanos, documentos sobre los feminicidios, escritura diarística, referencias a La muerte en Venecia de Mann y a Tres hermanas de Chejov, etc. No solo habla la dramaturga, sino que secciones enteras de la obra están puestas en

\footnotetext{
7 Mención nada casual, si recordamos que la dramaturga recurre a Bloom en su artículo de El País (Liddell 2016) para justificar el rechazo a toda connotación política del arte con citas de $E l$ canon occidental. A su vez este ensayo de Bloom se leyó como defensa de una forma de entender la academia frente a los cambios propuestos por corrientes como los Cultural Studies o la crítica feminista (Aradra y Pozuelo 2000: 33-63), que Bloom agrupó bajo el marbete "Escuela del Resentimiento" (Bloom 1994: 17).
} 
boca de Getse y Lola, actrices cuyo testimonio de maltrato es utilizado por Liddell como reflejo de su identidad fragmentada (Olivas Fuentes 2019: 640-641).

Desde el punto de vista de la autoconstrucción de la imagen liddelliana como feminista esta obra es interesante porque Liddell no solo introduce el diario en el que detalla las consecuencias de su ruptura con David Fernández (Olivas Fuentes 2019: 640) o los testimonios de maltrato de Lola y Getse (Liddell 2009: 41-43), sino que en un segmento titulado "Ejercicios de felicidad para hijos de puta" Angélica, Getse y Lola impostan la voz del paradigma de hombre, paradigma que es, sin ambages, machista. El hombre es capaz de menospreciar el dolor de las mujeres por el constructo teórico de la Humanidad que le permite, según la voz impostada por Getse, salvar su imagen moralmente intachable:

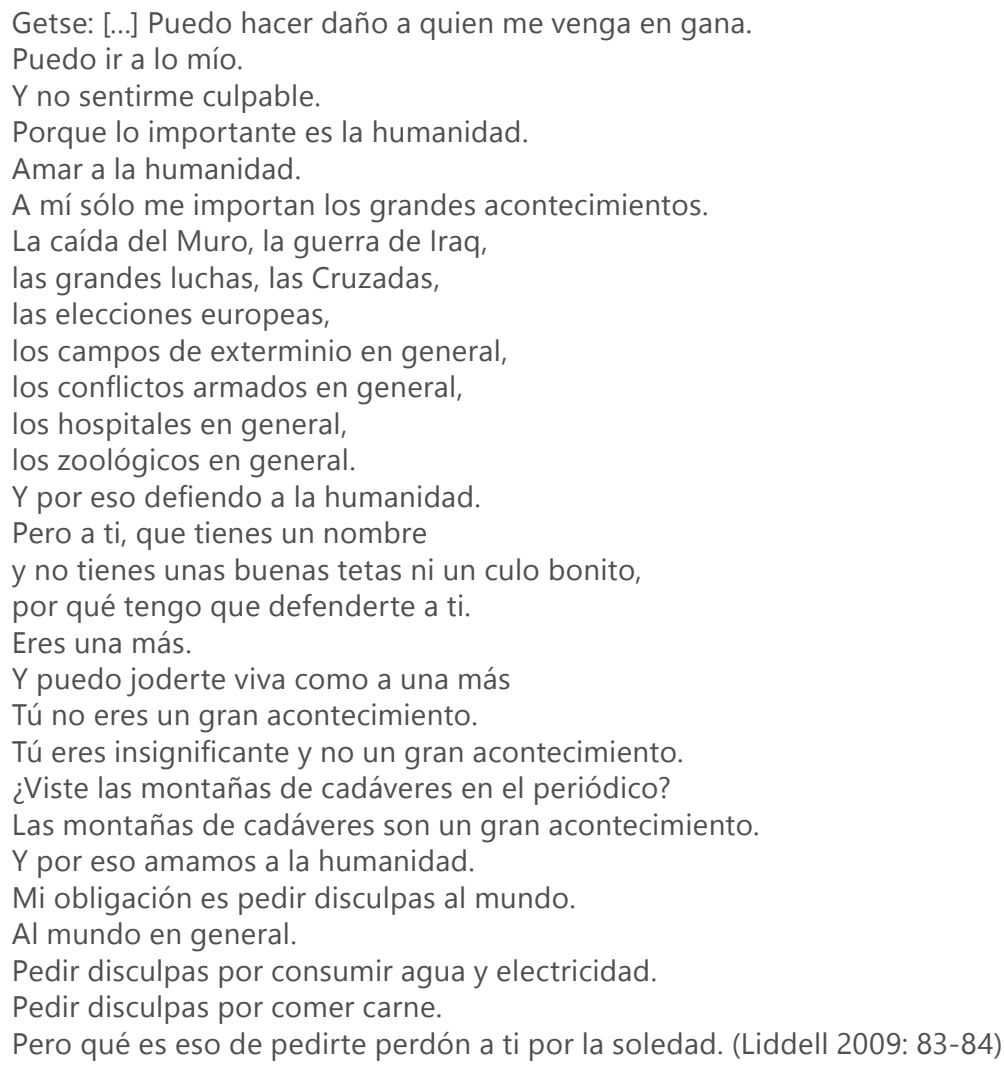

Liddell participa en este coro de denuncia mediante la exposición cruda de la incoherencia de un discurso masculino que justifica el sufrimiento femenino por su inadecuación al paradigma de lo que el hombre entiende como sufrimiento justificable: 
Angélica: [...] Si estuvieras enferma,

verdaderamente enferma,

entonces podrías hablarme de sufrimiento.

Ya sabes que solo tolero el sufrimiento de los enfermos

Aquel sufrimiento que está relacionado con lo estrictamente corporal.

Quejarse del dolor que causa un hueso roto es coherente.

O quejarse de una quemadura,

O quejarse de un dolor de estómago.

Por esa razón existe una ley que permite la tortura en ciertos casos.

La tortura física.

Porque el sufrimiento corporal es coherente.

Pero ese regodeo en el mundo del espíritu,

cuando uno lo posee todo en la vida,

Seguridad Social, subsidio por desempleo, protección

policial,

ese regodeo en el mundo del espíritu,

la depresión, la tristeza, la angustia, el llanto,

no es coherente, cojones.

Debes reconocerlo, no es coherente.

Así que bésame el puto culo, hostias.

Yo soy la especie luminosa

Porque por mi culpa sufren las mujeres.

O se internan en los manicomios.

O comen puñados de arsénico.

O llaman a su psiquiatra por las noches.

Y además me siento jodidamente orgulloso de ello. (Liddell 2009: 80-81)

Esta estrategia de impostar una voz orgullosa de sus atrocidades como forma de denunciarla ante el espectador fue una de las utilizadas por Liddell en sus Actos de resistencia contra la muerte, obras en las que la dramaturga y actriz recreaba el discurso de los hombres de Estado como exposición del machismo, el racismo y el antropocentrismo estructural de la sociedad española según el análisis ecofeminista que Celia Martínez propone de $Y$ los peces salieron a combatir contra los hombres y El año de Ricardo (Martínez Sáez 2017). Podríamos así cuestionarnos hasta qué punto La casa de la fuerza (2009) responde al teatro de tono político previo a lo que aquí he denominado el giro antirracionalista de Liddell, que, recordemos, sitúo aproximadamente en 2008. Liddell expresa de forma indirecta su concepción del pensamiento que "nace de lo oscuro" como la vía para aumentar la empatía entre seres humanos, frente al egoísmo que lleva la búsqueda de la satisfacción y la felicidad individual:

Angélica: [...] el pensamiento no es lo mismo que la opinión.

El pensamiento nace de lo oscuro.

Y la opinión nace de la satisfacción.

$Y$ yo soy un tío satisfecho [...]

¿Y qué sería del mundo que hemos conseguido

si sustituyéramos la opinión por el pensamiento?

Todo nuestro esfuerzo se iría a la mierda.

La gente empezaría a ponerse en el lugar del otro. 
Empezarían a sentirse culpables, a sentirse responsables, empezarían a sentir compasión, a cambiar su punto de vista.

Empezarían a ser bondadosos.

Y estamos aquí para ser felices.

No estamos aquí para ser bondadosos. (Liddell 2009: 79-80)

Solo a través de la asunción de que Liddell se adscribe a todo aquello que la voz del hombre machista rechaza podemos asumir que la fe en ese pensamiento oculto que funda la compasión por los otros frente al menosprecio del dolor individual justificado por la abstracción de la Humanidad (abstracción creada por los hombres según lo que ellos consideran lícito o no dentro de los dominios de la dignidad humana) responde a la visión del mundo de la autora. Si en obras posteriores, como el Ciclo de las resurrecciones o Una costilla sobre la mesa, una parte del ataque de Liddell a las mujeres se cifra en su incapacidad para aceptar la degradación como vía de acceso a lo humano, en La casa de la fuerza son los hombres los que, atrapados en su orgullo y en la defensa de la superioridad de lo masculino, se muestran incapaces de la empatía necesaria para comprenderse a ellos mismos. Esto lleva a la autora a cifrar en la angustia que provoca una acción incomprensible -la del incesto con sus propios hijos- la aniquilación de los "hombres fuertes" y su sustitución por los "hombres más frágiles del mundo" (2009: 120-122). También conlleva que Liddell exalte su poder y belleza en tanto que mujer ${ }^{8}$ como opuesto a esa idea de hombre:
Los hombres duros tienen el poder
pero yo, mujer, tengo el asco por los hombres.
[...]
Jamás volveré a emplear palabras indoloras.
La venganza femenina seguirá siendo el tema principal.
Ningún hombre ha conseguido igualar en belleza a una
mujer airada.
El destino de la belleza está, por tanto, en mis manos.
Desobedeceré. (Liddell 2009: 120-121)

De esta forma podemos concluir que en La casa de la fuerza están presentes los rasgos antimodernos que presiden desde 2008 la poética de Liddell: el recurso a la angustia y lo incomprensible como fundadores de una versión más humana de lo humano, la reivindicación de lo individual frente a las abstracciones colectivizantes $^{9}$ Ello es importante desde la perspectiva de la construcción de la misoginia de

\footnotetext{
${ }^{8}$ Esto no quiere decir que toda la imaginería que Liddell despliega en La casa de la fuerza con respecto a los atributos de los hombres y la condición de las mujeres sea hostil para ellos y beneficiosa para ellas. Por ejemplo, en el segmento titulado "Textos de amor a un muñeco de plastilina", Lola, Getse y Angélica proclaman su amor a un hombre cuya fuerza física le asimila a Dios, pero un dios capaz de ser "serio, solitario, callado y triste como las pesas" (2009: 93). Encontramos aquí prefiguraciones de los tonos místicos y de adoración de la belleza masculina que Liddell desarrollará posteriormente.

${ }^{9}$ De hecho, La casa de la fuerza coincide en el tiempo (y en la edición) con Anfaegtelse, texto en
} 
Liddell porque nos indica que la creación de un discurso de ataque a las mujeres no está necesariamente relacionada con su giro antirracionalista, sino que este admite modulaciones que generan otra imagen, más positiva, de la mujer y del género femenino. Si esto es así, ¿por qué la autora que en 2009 exaltaba la belleza de la mujer airada decidió exacerbar los tonos misóginos de sus obras posteriores?

\section{CONCLUSIONES}

Sostiene en su análisis Cristina Oñoro que en los espectáculos de Liddell el público "representa el papel de sociedad burguesa biempensante con la que la artista entra en conflicto y, dicho en sus propias palabras, 'se niega a hacer las paces'" (2021: 81). En gran medida es este conflicto con el público el que modula la construcción de la imagen que proyecta en escena (y que, dados los rasgos autoficcionales de su obra, acaba por mezclarse con ella misma). Así, cuando concebía el teatro como "una especie de activismo", su posición es la de una clara defensa de las mujeres y de su capacidad para rechazar la imposición de la maternidad, incluso cuando ello provocara el rechazo del poder y de cierto sector de las mujeres -según el testimonio de Puche y el reflejo de esta oposición en Belgrado-. Cuando Liddell abandona la fe en la capacidad política del teatro y pasa a concebir el arte como una oposición al "Estado hegeliano" y una búsqueda de la individualidad en lo prerracional del ser humano, las bases para su enfrentamiento con un feminismo que, de la mano de su Cuarta ola, tiene mayor capacidad para marcar la agenda política están servidas. Ello explicaría por qué entre el giro antirracional y antimoderno y obras de claro menosprecio a las mujeres como la Trilogía del infinito o Una costilla sobre la mesa -que confluyen en el espectáculo The Scarlet LetterLiddell es capaz de escribir un texto como La casa de la fuerza, en el que a una Humanidad abstracta secuestrada por lo masculino opone la individualidad y concreción del dolor femenino.

La casa de la fuerza ocuparía, pues, el ínterin entre un teatro político que acoge el feminismo como una de sus facetas y un teatro opuesto al "Estado hegeliano" en el que la Cuarta ola feminista se integra. Esta oposición perfila el dibujo misógino de Liddell en tanto que su alter ego escénico utiliza la retórica misógina como arma, en línea con toda una corriente de opinión que resalta lo que de puritano, censor y victimizador tiene el feminismo contemporáneo, cuya principal preocupación política es, según algunas teóricas feministas, la violencia sexual (Aguilar 2020: 136-137). A esta politización de las vivencias sexuales, Liddell responde resaltando la vinculación del sexo con lo apolítico, lo íntimo, lo oscuro del ser humano, y denostando a aquellas que se aferran al análisis social del sexo en busca de la "perfección" de las mujeres. Expresado de otra forma, Liddell quiere despolitizar el arte en un momento en el que las corrientes teóricas feministas buscan su politización; la dramaturga busca separar lo íntimo de lo colectivo al tiempo que la teoría feminista aboga por acercar lo personal a lo

la que Liddell cita pasajes de Temor y temblor de Kierkagaard, obra con la que había justificado en "Abraham y el sacrifico dramático" (2008b) su paso al absurdo y lo irracional como fundadores de lo humano. 
político. Liddell detecta en el feminismo un ataque a lo individual que antes era, en la visión del mundo que transmitía en unas obras abiertamente políticas, más propio del machismo. Así, en su visión, la "sociedad burguesa biempensante" a la que alude Oñoro habría pasado de ser biempensante por machista a ser biempensante por feminista. De esta forma es factible la especulación de que, sin el auge de la Cuarta ola feminista, las obras de Liddell hubieran mantenido los tonos de La casa de la fuerza. Podemos admitir que la dramaturga reajusta su personaje en función de lo que cree mejor para el arte: convertirse en la "parresiastés" contra el feminismo como corriente colectiva a partir de El centro del mundo.

Este reajuste de su personaje explicaría que pueda ir desde la sublimación de la mujer a su total menosprecio. Pudiera parecer una contradicción que este menosprecio se base en la creación de una imagen de lo femenino caracterizada por sus defectos -imagen presente en obras como El centro del mundo (2014), el Ciclo de las resurrecciones (2015), la Trilogía del infinito (2016) o Una costilla sobre la mesa (2018) como contraste con la imagen de la amada desde el paradigma de la literatura mística- y que al mismo tiempo Liddell reivindique la fundación de lo humano en lo oculto, en lo amoral, en lo irracional. ¿No formarían parte estos defectos de esa posibilidad de encontrar lo humano en lo que se oculta a lo consciente? La respuesta de Liddell es que no, dado que a pesar de que estos defectos se convierten en lo femenino por antonomasia en la retórica liddeIliana de la última década, las mujeres (feministas) no aceptan la imperfección como fundadora de lo humano; por el contrario, buscan la perfección a través de la organización colectiva, camino que Liddell descartó a partir de 2008. Así, no puede aceptar la "victimización" como forma de ganar un "suplemento de dignidad" que emplear en la lucha contra la discriminación social por cuanto todo camino que para ella no pase por plantear una revolución -necesariamente individual- en la concepción del ser humano es estéril. En tanto que esta lucha colectiva contra la discriminación por razón de género es un proyecto que impone la percepción de la dignidad humana según los parámetros para calibrar esta que estableció la Modernidad, el giro de Liddell hacia lo irracional (justificado teóricamente con Nietzsche y Kierkegaard) sitúa a la autora en una posición de potencial frontal oposición al feminismo percibido como proyecto político moderno.

Aunque en líneas generales la conclusión anterior sea válida, no se debe ocultar que el hecho de que Liddell construya su imagen a partir de su reivindicación de lo extracotidiano, de lo excesivo, conlleva que la artista desarrolle discursos y retóricas que pueden ser incompatibles entre sí. Por ejemplo, Liddell propone al mismo tiempo la aceptación de nuestras bajas pasiones -siempre que sean sublimes- y la rendición a un amor de tonos místicos, pero al mismo tiempo desactiva la validez de la retórica mística al reconocer que su amor es una invención producto de la necesidad de un sentido y al sugerir que es producto de una enfermedad mental (el síndrome de Clèrambault). La contradicción entre la imagen de sí misma que proyecta en La casa de la fuerza-claramente feminista- y en The Scarlet Letter -con tintes misóginos- se ve acentuada por lo 
excesivo de las estrategias de representación que utiliza para defender la capacidad cognitiva del descenso a lo amoral y el individualismo como potencial vía de mejora de la condición humana.

El ataque a las mujeres responde, de esta forma, no a una cosmovisión necesaria del mundo sino del arte y de su papel en la sociedad. En última instancia, pues, el registro misógino de la obra de Liddell $-y$, mediante el recurso a estrategias autoficcionales, de su proyección como artista- se constituye en una defensa de la autonomía del arte (y de la artista) con respecto a las percibidas exigencias de "corrección política" y de lo hegemónico. Como sostiene Cristina Oñoro, a pesar de que Liddell rechace la ideologización del arte, las posturas poéticas de la dramaturga se sostienen en una "concepción del artista que, aunque haya sido naturalizada, resulta tan ideológica como la concepción que la propia Liddell critica a los puritanos de nuestro tiempo" (2021: 75). Por cuanto la propia dramaturga ha expuesto los fundamentos de su ideología artística en lugares tan públicos como una tribuna de opinión en El País, una cabal interpretación -y análisis- de su propuesta estética deberá contar con su radical rechazo a la imposición de obligaciones morales más allá de su compromiso con los seres humanos como individuos (sean del género que sean).

\section{OBRAS CITADAS}

Aguilar Barriga, Nani (2020). "Una aproximación teórica a las olas del feminismo: la cuarta ola", Femeris, vol. 5, 2: 121-146. <https://doi.org/10.20318/femeris.2020.5387> (12 de febrero de 2021).

Anderson, Sherwood (1990). Winesburg, Ohio. Trad. A. Ros, ed. M. ${ }^{a}$ Eugenia Díaz. Madrid: Cátedra.

Aradra Sánchez, Rosa María y José María Pozuelo Yvancos (2000). Teoría del canon y literatura española. Madrid: Cátedra.

Ávalos, Almudena (2013). "Angélica Liddell: 'Soy una hooligan, una salvaje'", Smoda. El País. $\quad$ https://smoda.elpais.com/celebrities/angelica-liddell-soy-una-hooliganuna-salvaje/> (8 de febrero de 2021).

Barly, Daphne (2020). "Nietzsche y el feminismo: ¿Antagonista o precursor?", Carcaj. <http://carcaj.cl/nietzsche-y-el-feminismo-antagonista-o-precursor/> (12 de febrero de 2021).

Bloom, Harold (2019). El canon occidental. La escuela y los libros de todas las épocas [1994]. Trad. Damián Alou. Barcelona: Anagrama.

Checa Puerta, Julio Enrique (2019). "Angélica Liddell y su 'A' de artista: una revisión crítica de 'La letra escarlata'", Revista de escritoras ibéricas, 7: 153-186

Cornago, Óscar (2011). "Anotaciones al margen. Epílogo", in Angélica Liddell, La casa de la fuerza; Te haré invencible con mi derrota; Anfaegtelse. Segovia: La uÑa RoTa, 131-140.

Cultura y Deporte, ministerio de (2012). "Angélica Liddell, Premio Nacional de Literatura Dramática". <http://www.culturaydeporte.gob.es/actualidad/2012/11/20121105cu-lidell.html> (12 de febrero de 2021). 
Cultural, el (2007). "Angélica Liddell se alza con la II edición del Premio de Teatro ValleInclán". <https://elcultural.com/Angelica-Liddell-se-alza-con-la-II-edicion-delPremio-de-Teatro-Valle-Inclan> (4 de febrero de 2021).

Eguía Armenteros, Jesús (2017). "El mesianismo apocalíptico en el teatro de Angélica Liddell", in El teatro como documento artístico, histórico y cultural en los inicios del siglo xxı, ed. José Romera Castillo. Madrid: Verbum, 422-431

Fernández Peláez, Julio (2018). "El 'yo no ficcional' en la escena contemporánea española: de la autobiografía a la exposición", in Jóvenes plumas del hispanismo: nuevos retos y enfoques de la investigación filológica, ed. Juan Pedro Cabanilles Gomar. Madrid: Ediciones Complutense, 131-143.

Jabois, Manuel (2016). "'Un mundo sin dolor sería un mundo de imbéciles'", El País. <https://elpais.com/cultura/2016/10/06/actualidad/1475769790_702967.html> (5 de febrero de 2021).

Jiménez Carazo, Guillermo (2020). "Angélica Liddell, una creadora disidente que lleva al teatro el arte del dolor", elDiario.es. <https://www.eldiario.es/cultura/angelicaliddell-creadora-disidente-lleva-teatro-arte-dolor-vengo-quemar-padres-tresmeses-diferencia_1_6414987.html> (4 de febrero de 2021).

Liddell, Angélica (2003a). "El mono que aprieta los testículos de Pasolini", in El sacrificio como acto poético. Madrid: Continta Me Tienes, 2015, 33-43.

Liddell, Angélica (2003b). "Lesiones incompatibles con la vida", in El matrimonio Palavrakis; Once upon a time in West Asphixia. O hijos mirando al infierno; Hysterica Passio; Lesiones incompatibles con la vida. Bilbao: Artezblai, 2011.

Liddell, Angélica (2007). Belgrado. Canta lengua el misterio del cuerpo glorioso. Bilbao: Artezblai, 2008.

Liddell, Angélica (2008a). "El sobrino de Rameau visita las cuevas rupestres", in El sacrificio como acto poético. Madrid: Continta Me Tienes, 2015, 67-92.

Liddell, Angélica (2008b). "Abraham y el sacrificio dramático", in El sacrificio como acto poético. Madrid: Continta Me Tienes, 2015, 99-118.

Liddell, Angélica (2009). La casa de la fuerza, in La casa de la fuerza; Te haré invencible con mi derrota; Anfaegtelse. Segovia: La uÑa RoTa, 2011.

Liddell, Angélica (2014). El centro del mundo. Segovia: La uÑa RoTa.

Liddell, Angélica (2015). Ciclo de las resurrecciones. Segovia: La uÑa RoTa.

Liddell, Angélica (2016a). "La poesía es la rebelión contra el Estado", El País. <https://elpais.com/cultura/2016/02/09/babelia/1455042695_683519.html> (5 de febrero de 2021).

Liddell, Angélica (2016b). Trilogía del infinito. Segovia: La uÑa RoTa.

Liddell, Angélica (2018). Una costilla sobre la mesa. Segovia: La uÑa RoTa.

Lijmaer, Lucía (2019). Ofendiditos. Sobre la criminalización de la protesta. Barcelona: Anagrama.

Martínez Sáez, Celia (2017): "El cuerpo que cuestiona: Una lectura ecofeminista de las obras Y los peces salieron a combatir contra los hombres (2003) y El año de Ricardo (2005) de Angélica Liddell", Letras Hispanas: Revista de literatura y de cultura, 13.1: 231-242. 
Monti, Silvia (2019). "Máscara, persona y personaje en el teatro de Angélica Liddell", in Teatro, (auto)biografía y autoficción (2000-2018): En homenaje al profesor José Romera Castillo, ed. Guillermo Laín Corona y Rocío Nogales Santiago. Madrid: Visor, 529-542.

Morón Espinosa, Antonio (2017): "La utilización del teatro documento en La casa de la fuerza, de Angélica Liddell", in El teatro como documento artístico, histórico y cultural en los inicios del siglo xxı, ed. José Romera Castillo. Madrid: Verbum, 432-441.

Nietzsche, Friedrich (2010). Así habló Zaratustra. Un libro para todos y para nadie. Trad. José Rafael Hernández Arias. Madrid: Gredos.

Olivas Fuentes, Marta (2019). "Hacia una aplicación del término autoficción en el teatro. Algunas reflexiones sobre Anfaegtelse y La casa de la fuerza, de Angélica Liddell", in Vir bonus dicendi peritus: homenaje al profesor Miguel Ángel Garrido Gallardo, ed. Luis Alburquerque García y José Luis García Barrientos. Madrid: CSIC, 634-643.

Oñoro Otero, Cristina, (2021). "Puritanismo, mirada masculina y espectadoras: 'The Scarlet Letter' (2018), de Angélica Liddell", Tropelías: Revista de Teoría de la Literatura y Literatura Comparada, 35: 70-85.

Ordóñez, Marcos (2020). "Quien manda es ella", El País. <https://elpais.com/cultura/2020/07/09/babelia/1594283232_875601.html> (4 de febrero de 2021).

Postigo Asenjo, Marta (2007). "Mujer, feminismo y modernidad: atrapadas entre lo público y lo privado", Thémata: Revista de filosofía, 39: 281-286

Puche, Gumersindo (2007). "Mirar el daño: a propósito de Lesiones incompatibles con la vida, acción que cierra El tríptico de la aflicción", in 50 años de teatro contemporáneo: temática y autores, ed. Antonia García Tirado y Julio Enrique Checa Puerta. Madrid: Secretaría General Técnica, 27-38.

Vicente, Álex (2019). "Angélica Liddell carga sobre el escenario contra el \#MeToo", El País. <https://elpais.com/cultura/2019/02/13/actualidad/1550084229_993210.html> (4 de febrero de 2021).

Vidales, Raquel (2018). "¿Por qué dejamos marchar a Angélica Liddell?". <https://elpais. com/cultura/2018/05/29/actualidad/1527594784_289245.html> (4 de febrero de 2021).

Vilches de Frutos, María Francisca (2009): "Representaciones de género en las artes escénicas: Angélica Liddell y el discurso de la transgresión", Hispanística XX, 27: 261-276.

Villora, Pedro M. (2009): "Ayer y hoy de Angélica Liddell", in Angélica Liddell, Frankenstein; La historia es domadora del sufrimiento: 2006. Sigüenza: Eugenio Cano Editor, 7-11. 